\title{
Understanding Violence Against Chinese Women in Hong Kong
}

\section{An Analysis of Risk Factors With a Special Emphasis on the Role of In-Law Conflict}

Ko Ling Chan

University of Hong Kong

Douglas A. Brownridge

University of Manitoba

Agnes Tiwari

Daniel Y. T. Fong

University of Hong Kong

Wing-Cheong Leung

Kwong Wah Hospital

\begin{abstract}
This study examines risk factors of intimate partner violence against women in a cohort of Chinese women drawn from a large representative sample in Hong Kong. Data from a cross-section of 1,870 women are analyzed. Prevalence rates of women's self-reports of violence by their intimate partners and conflict with in-laws are computed and compared in terms of demographic and socioeconomic characteristics. The results show that in-law conflict was the characteristic most significantly associated with women's reports of violent victimization. This suggests that in-law conflict should be included in the screening and assessment of risk for intimate partner violence.
\end{abstract}

Keywords: Chinese; in-law conflict; intimate partner violence

$\mathrm{V}$

iolence against women is a serious social problem in Chinese societies. The lifetime prevalence of spousal violent victimization in China ranges from $1.8 \%$ to $50 \%$ (Hicks \& Li, 2003; Leung, Ng, Leung, \& Ho, 2003; Yick, 1999; Yick \& Agbayani-Siewert, 2000), and the lifetime prevalence of perpetration has been estimated at $17 \%$ (Parish, Wang, Laumann, Pan, \& Luo, 2004), depending on the samples and instruments used. With regard to the annual prevalence of spousal violence, estimates of victimization range from $16 \%$ to $26 \%$ (Leung, Leung, Lam, \& Ho,

Authors' Note: This study is commissioned by the Social Welfare Department and the Government of Hong Kong and funded by the Lotteries Fund. 
1999; Xu et al., 2005). In a sample of Chinese women attending an antenatal clinic in Hong Kong, it was found that $17.9 \%$ had a history of abuse, $15.7 \%$ reported being abused in the preceding year, and $4.3 \%$ were abused during their current pregnancy (Leung et al., 1999). In another sample of Chinese women attending an outpatient gynecological clinic in mainland China, $43 \%$ reported abuse in their lifetime, and $26 \%$ reported abuse in the preceding year (Xu et al., 2005).

The study of risk factors is an important research agenda in the public health approach to preventing intimate partner violence (IPV; Mercy, Rosenberg, Powell, Broome, \& Roper, 1993). A large number of studies have provided a comprehensive profile of the universal risk factors associated with IPV to help understand the phenomenon and thus identify effective prevention strategies to reduce violence (Krug, Dahlberg, Mercy, Zwi, \& Lozaro, 2002). Although the phenomenon of IPV is found across different countries and cultures, universal risk factors may not adequately address IPV in Chinese societies. Although the number of studies of spousal violence in Chinese societies has been increasing during the past decade, more studies are needed to identify culture-specific patterns of spousal violence and risk factors.

The existing approach to studying risk factors specific to IPV in Chinese societies mainly involves determining whether universal risk factors are also applicable to the Chinese. In general, the demographic and socioeconomic factors that have been found to correlate with IPV in Chinese populations are similar to those reported in Western studies. With regard to abusers' characteristics, Chinese abusive partners tend to be unemployed or of a low socioeconomic status (Leung et al., 1999; Parish et al., 2004; Xu et al., 2005; Yick, 2000); to abuse alcohol and drugs (Liu \& Zhang, 2005; Parish et al., 2004; Xu et al., 2005); to have a gambling problem (Liu \& Zhang, 2005); to be young (Tang, 1999); to have a sense of insecurity, an aggressive personality, poor anger management, and a lack of empathy (Chan, 2004); to have psychological disorders (Liu \& Zhang, 2005); and/or to suffer from sexual jealousy (Parish et al., 2004). With regard to social and cultural factors, women's subordination (Liu \& Chan, 1999) and male domination (Xu et al., 2005) are regarded as important risk factors that contribute to violence against women in China. Although these studies tested the applicability of theories developed for Western cultures in a Chinese context, they have not adequately addressed cultural and social characteristics that are specific to Chinese societies.

\section{Relationship Between In-law Conflict and IPV}

There is a growing recognition that women's experiences of oppression and victimization are different across cultures and even within the same culture. In a qualitative study of a cohort of 15 battered Indian brides, Fernandez (1997) argued that unlike the typical domestic violence scenario in the West that usually involves a lone man battering a lone woman, violence against women in Asia usually involves the husband's family —in particular, senior women such as the wife's mother-in-law. 
Other studies in Indian, Indo-Fijian, and Taiwanese cultures (Counts, Brown, \& Campbell, 1999) have similarly found that the mother-in-law plays a role in wife beating and that this is probably common in collectivist societies in general.

The mother-in-law may be a perpetrator of violence against women (Ramanathan, 1996; Rianon \& Shelton, 2003), including women who are pregnant (Dasgupta, 2000; Leung et al., 1999). A recent study of South Asians in the United States found a significant relationship between IPV and emotional abuse by in-laws (Raj, Livramento, Santana, Gupta, \& Silverman, 2006). Conflict with a mother-inlaw has also been associated with wives' postnatal depression (Lee, Yip, Leung, \& Chung, 2004) and violence by husbands (Chan, 2006; Liu, 2002). Indeed, in such situations, the husband may be a passive observer of violence by in-laws, or he may be a participant in his wife's battering.

This study focuses mainly on in-law conflict, which is more common than in-law abuse. Existing studies of in-law conflict as a risk factor for IPV have mainly used case studies or qualitative studies with small samples, so reliable analyses were not possible and the findings had limited generalizability. Until now, data have not been available to quantitatively examine in-law conflict as a risk factor of IPV. To fill this research gap, we attempted to quantify the levels of in-law conflict and to examine the correlation between in-law conflict and IPV against women in a cohort of Chinese women in Hong Kong.

\section{Method}

\section{Design and Sample}

This study was part of a larger study that was carried out in Hong Kong between December 2003 and August 2004. The larger study was the first of its kind conducted in Hong Kong to examine the prevalence and risk factors of spouse battering and child abuse. A total of 4,347 valid quarters were randomly sampled from the Register of Quarters maintained by the Census and Statistics Department of the Government of Hong Kong. This was the most up-to-date and complete sampling frame available in Hong Kong. A stratified sample design was adopted, with the records in the Register of Quarters first stratified by geographic area and type of quarters. Selection of sampling units using a systematic replicate sampling technique was used with fixed sampling intervals and nonrepetitive random numbers. The use of replicated sampling facilitated the calculation of sampling errors and ensured that the required effective sample size would be met by adjusting the number of replicates used. Only about $6 \%$ of the sample was subject to a clustering effect where more than one target respondent was in a single household. Thus, the impact on the variances (or sampling errors) used in statistical tests in the sample is likely to be negligible. A total of 3,049 quarters were successfully enumerated, representing a 
response rate of $70 \%$. Nonparticipation encompassed both refusals to respond (20\%) and a failure to contact potential respondents (10\%).

All family members that met the study criteria during the study period were invited to participate. Eligible participants for the study were aged 16 or older, gave their informed consent, were married or cohabitated, with or without children, and were Cantonese, Putonghua, or English speaking. The participants were interviewed face to face by interviewers who were trained to conduct household research interviews. A research unit that specializes in conducting face-to-face household surveys was responsible for employing and training about 100 interviewers. Additional training on the ethical procedures for handling participants reporting violence incidents was provided by the first author. The procedures were approved by the ethics committee of the University of Hong Kong.

A total of 5,049 adult respondents were successfully interviewed. The overall response rate was $71 \%$. About $46.4 \%$ were male and $53.6 \%$ were female. Virtually all $(99.5 \%)$ were Chinese. About $88.5 \%$ were married and a further $6.4 \%$ were widowed. Only about $1.9 \%$ were in a cohabiting union with their intimate partner.

The data employed in this analysis were a subsample from the household survey. All female respondents living with their partners were selected. A total of 1,870 women with complete records on characteristics of their partners were included in this analysis. The mean age difference between spouses was $4.5(S D=4.5)$, and about $14 \%$ of the couples had an age difference of more than 10 years. Most of the respondents and their partners had at least a junior middle school (equivalent to Grades 7 to 9 in the United States) or higher education (62\% and 65\%, respectively) and were married or cohabiting (98\%).

\section{Measures}

Dependent variables. The Revised Conflict Tactics Scale (CTS2) was employed to measure physical violence in terms of lifetime and preceding-year prevalence. The CTS2 covers five aspects of spousal conflicts-negotiation, physical assault, psychological aggression, physical injury, and sexual coercion-and has been widely adopted to measure different types of spousal conflicts. Its psychometric characteristics are well documented (Straus, 1990). According to the findings of previous studies, the internal consistency reliability of the CTS2 scales is generally high, with an alpha coefficient ranging from .79 to .95 (Straus, Hamby, BoneyMcCoy, \& Sugarman, 1996), and it has high cross-cultural reliability (Straus, 2004). With respect to criterion validity, an increasing severity of tactics has been shown to correlate with increasing injury severity (Coben, Forjuoh, \& Gondolf, 1999). The CTS2 has been translated into Chinese by the first author and validated using Hong Kong data (Chan, 2004). In this study, the Chinese translation of the CTS2 has satisfactory reliability ( $\alpha$ ranged from .88 to .96 ) and validity. 
In the present study, male partner violence against women was defined as acts of physical assault (being grabbed, pushed, or shoved; being slapped; having something thrown that could hurt; one's arm or hair being twisted; being threatened with or having a knife or gun used; being punched or hit with something that could hurt; being choked; being slammed against a wall; being beaten; being burned or scalded; or being kicked) perpetrated by a woman's current marital or common-law partner within a specified time frame preceding the interview. The recall time frame was confined to the preceding year and the lifetime of the relationship. Respondents who reported any of the aforementioned acts by their partner in the preceding year and in the lifetime of their relationship were coded as having experienced IPV.

Independent variables. The Demographic Questionnaire was used to detect the demographic and socioeconomic characteristics of the participants and to estimate correlations with IPV against women. The questionnaire included items asking for information about the respondent's and her spouse's age, the age difference between her and her spouse, her and her spouse's education level, her marital status, whether she was a new arrival to Hong Kong, her and her spouse's work status and income, her family income, whether she was receiving social security, whether she or her spouse had indebtedness, and whether she or her spouse were alcoholics and drug abusers.

One question was used to measure the frequency of in-law conflict. The participants and their male partners were asked at the interview to report the number of incidents of conflict with parents-in-law in the previous 12 months. The responses included never, once, twice, 3 to 5 times, 6 to 10 times, 11 to 20 times, 20 times or more, and none in the past 12 months but it has happened before.

A social support scale from the Family Needs Screener (FNS; Kantor \& Straus, 1999) was adopted. The FNS is a short version of the Personal and Relationships Profile, which is a multi-scale instrument that provides a profile of scores for variables that have an empirically demonstrated relationship with physical violence against a spouse in a marital, cohabiting, or dating relationship, with satisfactory internal reliability (Straus \& Mouradian, 1999). The social support scale is a 10-item scale. It has been translated into Chinese by the first author. A back translation was conducted to compare differences. The Chinese version was further checked by two clinical psychologists and three experienced social workers who have been working with family violence. In this study, the alpha coefficients of the Chinese translation of the social support scale were .73 for all respondents, .72 for male respondents, and .74 for female respondents. During the interview, respondents were asked to respond to the items (only have a few friends/family to help with baby/children, feel very isolated, someone who makes me feel confident, someone I can talk to openly, someone I can talk to about my relationship problems, have someone to borrow money from in an emergency, have someone to take care of my children, have someone who helps me around the house, have someone I can count on in times of need, and don't have enough money for my daily needs) and indicate the extent to which they agreed 
that the statement described themselves, using the following response categories: strongly disagree (1), disagree (2), agree (3), and strongly agree (4).

Participation in the study was voluntary and informed consent was provided. Confidentiality was guaranteed. Once identified as abused, participants were encouraged to seek help and were provided with the necessary information for referral.

\section{Statistical Analyses}

The demographic characteristics of the abused and nonabused women were summarized and compared through the use of crude odds ratios (ORs). To examine the association of demographics (Group 1-respondent's and her spouse's age, the age difference between her and her spouse, her and her spouse's education level, her marital status, and whether she was new arrival to Hong Kong), socioeconomic status (Group 2-her and her spouse's work status and income, her family income, whether she was receiving social security, and whether she or her spouse had indebtedness), social support and substance abuse (Group 3-social support and whether she or her spouse were alcoholics and drug abusers), and women's and husband's inlaw conflict (Group 4) with IPV in the preceding year and the lifetime period, a structured multiphase logistic regression analysis was performed with sequential causal relationships between the variables (Lam, Fong, Lauder, \& Lam, 2002). Figure 1 provides a diagram of the analytical plan to account for sequential causal relationships between variables.

Specifically, we hypothesized that the variables in Group 1 may affect the variables in Group 2, but not vice versa, and similarly that the variables in Groups 1 and 2 may affect those in Group 3, but not vice versa, and so on. Phase 1 of the analysis was a forward stepwise logistic regression of all variables in Group 1. In Phase 2, a forward stepwise logistic regression was performed on the Group 2 variables after force entering those variables that were significant in the Phase 1 analysis. In Phase 3, a forward stepwise logistic regression was performed on the Group 3 variables after force entering those variables that were significant in Phase 1 and those that were significant in Phase 2. The Phase 4 analysis was conducted in a similar fashion. The effects of the variables in Group 1 were examined in Phase 1, those in Group 2 were examined in Phase 2, and so on.

The same approach of a structured multiphase logistic regression analysis was performed on the sequential causal relationships between the variables to examine the association of demographics (Group 1), socioeconomic status (Group 2), social support and substance abuse (Group 3), and husband's in-law conflict (Group 4) with women's in-law conflict.

The Hosmer and Lemeshow (2000) (H-L) test was used to assess the goodness of fit of the logistic regression analysis. A nonsignificant result implies adequacy of the logistic model. The effects of demographics and socioeconomic status on the experience of women's in-law conflict were examined by a similar structured multiphase logistic regression analysis consisting of three phases. 


\section{Figure 1}

\section{Diagram of Analytical Plan to Account for Sequential Causal Relationships Between Independent Variables}

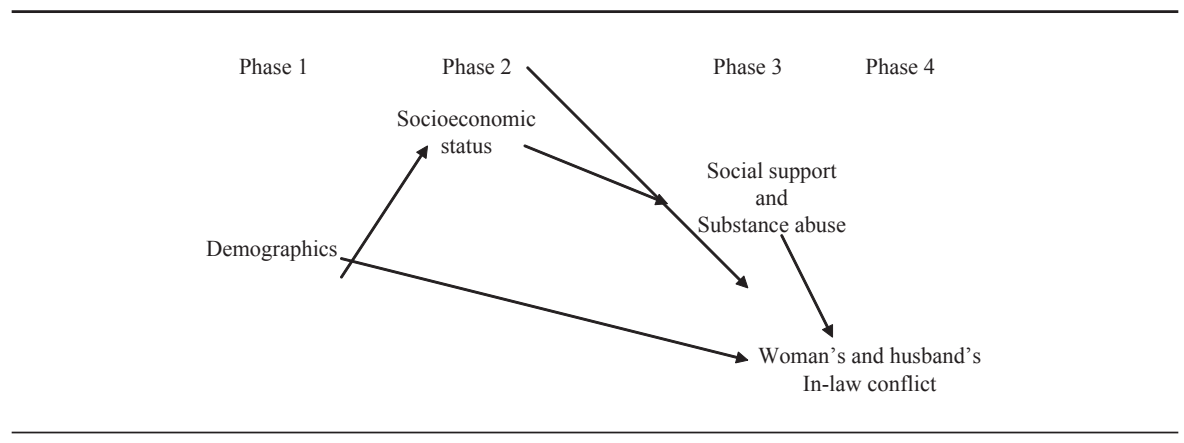

The nominal level of significance was taken as 5\% and Statistical Package for the Social Sciences Version 14 was used for the statistical analysis.

\section{Results}

\section{Prevalence}

The lifetime prevalence of physical abuse was $8.5 \%$, and the prevalence of preceding-year abuse was $4.5 \%$. The lifetime prevalence of severe and less severe physical violence were $3.4 \%$ and $8.3 \%$, respectively; the prevalence of precedingyear severe and less severe physical violence were $1.3 \%$ and $4.4 \%$, respectively. Of the respondents who were physically abused in their lifetime, $39.6 \%$ were injured and $38.4 \%$ were sexually abused by their partners. Of those physically abused in the preceding year, $32.1 \%$ were injured and sexually abused by their partners. With regard to in-law conflict, about $4.9 \%$ of female respondents and $3.6 \%$ of their male partners reported having conflict with their in-laws in the preceding year.

\section{Risk Factors}

Tables 1, 2, and 3 present the descriptive statistics as well as the univariate logistic regression results for the demographic, socioeconomic, relationship, and behavioral risk factors.

There were 14 risk factors that were significant $(p<.05)$ for lifetime IPV. Respondents and their partners who were young ( 34 or younger) (ORs $=1.96$ and 
Table 1

Demographic Characteristics of Respondents $(N=1,870)$ and Partners and Their Association With Lifetime and Preceding-Year Intimate Partner Violence (IPV) as Reported With Univariate Regression Analyses

\begin{tabular}{|c|c|c|c|c|c|}
\hline Characteristic & $N$ & $\begin{array}{l}\text { Lifetime } \\
\text { Prevalence } \\
\text { of IPV }\end{array}$ & $\begin{array}{c}\text { Crude OR } \\
(95 \% \text { CI }) \\
\text { Lifetime }\end{array}$ & $\begin{array}{l}\text { Preceding- } \\
\text { Year } \\
\text { Prevalence } \\
\text { of IPV }\end{array}$ & $\begin{array}{c}\text { Crude OR } \\
\text { Crude OR } \\
(95 \% \text { CI) } \\
\text { Preceding Year }\end{array}$ \\
\hline \multicolumn{6}{|l|}{ Age group of wife } \\
\hline Younger than 34 & 305 & $12.13 \%$ & $1.958 *(1.164,3.294)$ & $7.87 \%$ & $4.917 *(2.090,11.569)$ \\
\hline 35 to 54 & 1,116 & $8.51 \%$ & $1.320(0.847,2.056)$ & $4.75 \%$ & $2.870 *(1.294,6.366)$ \\
\hline 55 or older & 410 & $6.59 \%$ & 1.000 & $1.71 \%$ & 1.000 \\
\hline \multicolumn{6}{|l|}{ Age group of husband } \\
\hline Younger than 34 & 169 & $14.20 \%$ & $2.052 *(1.205,3.493)$ & $9.47 \%$ & $3.439 *(1.698,6.964)$ \\
\hline 35 to 54 & 1,086 & $8.47 \%$ & $1.147(0.787,1.673)$ & $4.70 \%$ & $1.620(0.927,2.832)$ \\
\hline 55 or older & 576 & $7.47 \%$ & 1.000 & $2.95 \%$ & 1.000 \\
\hline $\begin{array}{l}\text { Spouse age difference } \\
\quad \text { years, } M(S D)\end{array}$ & \multicolumn{4}{|c|}{ Spouse age difference, } & $1.005(0.957,1.054)$ \\
\hline \multicolumn{6}{|c|}{ Education } \\
\hline F3 or below & 1,123 & $8.46 \%$ & $0.899(0.508,1.593)$ & $3.92 \%$ & $0.506 *(0.261,0.981)$ \\
\hline F4 to F7 & 548 & $8.94 \%$ & $0.956(0.521,1.754)$ & $5.11 \%$ & $0.669(0.332,1.347)$ \\
\hline Tertiary or above & 161 & $9.32 \%$ & 1.000 & $7.45 \%$ & 1.000 \\
\hline \multicolumn{6}{|l|}{ Education (husband) } \\
\hline F3 or below & 1,078 & $8.16 \%$ & $0.907(0.545,1.507)$ & $3.62 \%$ & $0.663(0.341,1.288)$ \\
\hline $\mathrm{F} 4$ to $\mathrm{F} 7$ & 530 & $9.62 \%$ & $1.086(0.631,1.868)$ & $6.23 \%$ & $1.173(0.594,2.315)$ \\
\hline Tertiary or above & 224 & $8.93 \%$ & 1.000 & $5.36 \%$ & 1.000 \\
\hline \multicolumn{6}{|l|}{ Marital status } \\
\hline Married & 1,796 & $8.63 \%$ & $0.756(0.264,2.165)$ & $4.45 \%$ & $0.373(0.129,1.080)$ \\
\hline Cohabited & 36 & $11.11 \%$ & 1.000 & $11.11 \%$ & 1.000 \\
\hline \multicolumn{6}{|l|}{ New arrival } \\
\hline Yes & 123 & $11.38 \%$ & $1.383(0.773,2.476)$ & $8.94 \%$ & $2.198 *(1.133,4.264)$ \\
\hline No & 1,683 & $8.50 \%$ & 1.000 & $4.28 \%$ & 1.000 \\
\hline
\end{tabular}

Note: $\mathrm{OR}=$ odds ratio $\mathrm{CI}=$ confidence interval.

$* p<.05$.

2.05, respectively), were both currently in debt ( $\mathrm{ORs}=3.22$ and 2.54, respectively), who abused alcohol and drugs (ORs $=1.90$ to 4.61, respectively), and who experienced conflict with in-laws (ORs $=4.12$ and 2.72, respectively) had the highest odds ratios. Receiving more social support was a significant $(p<.05)$ protective factor $(\mathrm{OR}=0.52)$. Respondents who were employed, those who earned their own income, and those with a higher level of family income had higher odds of violence. A similar pattern was found for preceding-year IPV such that respondents who had a higher level of education, those who were employed, and those who earned more income had higher odds. Most of the remaining risk and protective factors were 
Table 2

Socioeconomic Characteristics of Respondents $(N=1,870)$ and Partners and Their Association With Lifetime and Preceding-Year Intimate Partner Violence (IPV) as Reported With Univariate Regression Analyses

\begin{tabular}{|c|c|c|c|c|c|}
\hline Characteristic & $N$ & $\begin{array}{l}\text { Lifetime } \\
\text { Prevalence } \\
\text { of IPV }\end{array}$ & $\begin{array}{l}\text { Crude OR } \\
\text { (95\% CI) } \\
\text { Lifetime }\end{array}$ & $\begin{array}{l}\text { Preceding- } \\
\text { Year } \\
\text { Prevalence } \\
\text { of IPV }\end{array}$ & $\begin{array}{c}\text { Crude } \\
\text { OR } \\
(95 \% \mathrm{CI}) \\
\text { Preceding Year }\end{array}$ \\
\hline \multicolumn{6}{|l|}{ Work status } \\
\hline Unemployed & 1,041 & $7.20 \%$ & $0.653 *(0.472,0.905)$ & $3.36 \%$ & $0.527 *(0.338,0.821)$ \\
\hline Employed & 791 & $10.62 \%$ & 1.000 & $6.19 \%$ & 1.000 \\
\hline \multicolumn{6}{|l|}{ Work status (husband) } \\
\hline Unemployed & 507 & $7.50 \%$ & $0.806(0.551,1.179)$ & $2.96 \%$ & $0.555^{*}(0.314,0.979)$ \\
\hline Employed & 1,325 & $9.13 \%$ & 1.000 & $5.21 \%$ & 1.000 \\
\hline \multicolumn{6}{|l|}{ Income group } \\
\hline No income & 923 & $6.61 \%$ & $0.524 *(0.371,0.741)$ & $3.03 \%$ & $0.397 *(0.248,0.636)$ \\
\hline$\$ 4,999$ or below & 200 & $7.00 \%$ & $0.558(0.309,1.006)$ & $2.00 \%$ & $0.259 *(0.092,0.725)$ \\
\hline$\$ 5,000$ or above & 698 & $11.89 \%$ & 1.000 & $7.31 \%$ & 1.000 \\
\hline \multicolumn{6}{|c|}{ Income group (husband) } \\
\hline No income & 450 & $7.78 \%$ & $0.799(0.539,1.184)$ & $3.11 \%$ & $0.546 *(0.304,0.981)$ \\
\hline$\$ 4,999$ or below & 135 & $4.44 \%$ & $0.440(0.190,1.021)$ & $0.74 \%$ & $0.127 *(0.017,0.922)$ \\
\hline$\$ 5,000$ or above & 1,225 & $9.55 \%$ & 1.000 & $5.55 \%$ & 1.000 \\
\hline \multicolumn{6}{|l|}{ Low-income family } \\
\hline $\begin{array}{l}\text { Low-income family } \\
\text { (less than } \$ 10,000\end{array}$ & 0) 487 & $6.37 \%$ & $0.646 *(0.430,0.971)$ & $1.64 \%$ & $0.279 * * *(0.134,0.582)$ \\
\hline $\begin{array}{l}\text { Not "low-income } \\
\text { family" } \\
(\geq \$ 10,000)\end{array}$ & 1,345 & $9.52 \%$ & 1.000 & $5.65 \%$ & 1.000 \\
\hline \multicolumn{6}{|l|}{ Social security } \\
\hline $\begin{array}{l}\text { Receiving social } \\
\text { security }\end{array}$ & 99 & $11.11 \%$ & $1.350(0.705,2.585)$ & $4.04 \%$ & $0.869(0.311,2.423)$ \\
\hline No social security & 1,687 & $8.48 \%$ & 1.000 & $4.62 \%$ & 1.000 \\
\hline \multicolumn{6}{|l|}{ Debt } \\
\hline Indebtedness & 77 & $22.08 \%$ & $3.222 * * *(1.829,5.676)$ & $6.49 \%$ & $1.479(0.581,3.769)$ \\
\hline Not in debt & 1,695 & $8.08 \%$ & 1.000 & $4.48 \%$ & 1.000 \\
\hline \multicolumn{6}{|l|}{ Debt (husband) } \\
\hline Indebtedness & 106 & $17.92 \%$ & $2.536 * * *(1.497,4.297)$ & $5.66 \%$ & $1.272(0.541,2.993)$ \\
\hline Not in debt & 1,665 & $7.93 \%$ & 1.000 & $4.50 \%$ & 1.000 \\
\hline
\end{tabular}

Note: $\mathrm{OR}=$ odds ratio $; \mathrm{CI}=$ confidence interval.

$* p<.05 . * * * p<.001$.

similarly related to preceding-year IPV as they were to lifetime IPV. However, unlike with the lifetime IPV, indebtedness was not significantly associated with preceding-year IPV. Conversely, although women who had recently immigrated to Hong Kong did not have significantly greater odds of violence in their lifetime, they did have significantly higher odds of preceding-year IPV $(\mathrm{OR}=2.20)$. 
Table 3

Relationship and Behavioral Characteristics of Respondents $(N=1,870)$ and Partners and Their Association With Lifetime and Preceding-Year Intimate Partner Violence (IPV) as Reported With Univariate Regression Analyses

\begin{tabular}{|c|c|c|c|c|c|}
\hline Characteristic & $N$ & $\begin{array}{l}\text { Lifetime } \\
\text { Prevalence } \\
\text { of IPV }\end{array}$ & $\begin{array}{c}\text { Crude OR } \\
(95 \% \mathrm{CI}) \\
\text { Lifetime }\end{array}$ & $\begin{array}{l}\text { Preceding- } \\
\text { Year } \\
\text { Prevalence of } \\
\text { IPV }\end{array}$ & $\begin{array}{c}\text { Crude OR } \\
(95 \% \mathrm{CI}) \\
\text { Preceding Year }\end{array}$ \\
\hline Social support, $M(S D)$ & 1,825 & & $0.524 *(0.318,0.865)$ & & $0.489 *(0.252,0.947)$ \\
\hline $\begin{array}{l}\text { Social support } \\
\text { (husband), } M(S D)\end{array}$ & 1,812 & & $0.585(0.340,1.009)$ & & $0.675(0.323,1.408)$ \\
\hline \multicolumn{6}{|l|}{ Women's in-law conflict } \\
\hline $\begin{array}{l}\text { Yes } \\
\text { No }\end{array}$ & $\begin{array}{r}89 \\
1,743\end{array}$ & $\begin{array}{r}25.84 \% \\
7.80 \%\end{array}$ & $\begin{array}{l}4.118 * * *(2.483,6.829) \\
1.000\end{array}$ & $\begin{array}{r}15.73 \% \\
4.02 \%\end{array}$ & $\begin{array}{l}4.461 * * *(2.403,8.282) \\
1.000\end{array}$ \\
\hline \multicolumn{6}{|l|}{ Husband's in-law conflict } \\
\hline $\begin{array}{l}\text { Yes } \\
\text { No }\end{array}$ & $\begin{array}{r}66 \\
1,766\end{array}$ & $\begin{array}{r}19.70 \% \\
8.27 \%\end{array}$ & $\begin{array}{l}2.722 * *(1.450,5.109) \\
1.000\end{array}$ & $\begin{array}{r}13.64 \% \\
4.25 \%\end{array}$ & $\begin{array}{l}3.560 * * *(1.698,7.462) \\
1.000\end{array}$ \\
\hline \multicolumn{6}{|l|}{ Alcohol abuse } \\
\hline $\begin{array}{l}\text { Yes } \\
\text { No }\end{array}$ & $\begin{array}{r}99 \\
1,733\end{array}$ & $\begin{array}{r}18.18 \% \\
8.14 \%\end{array}$ & $\begin{array}{l}2.509 * * *(1.464,4.301) \\
1.000\end{array}$ & $\begin{array}{r}10.10 \% \\
4.27 \%\end{array}$ & $\begin{array}{l}2.519 * *(1.259,5.042) \\
1.000\end{array}$ \\
\hline \multicolumn{6}{|l|}{ Alcohol abuse (husband) } \\
\hline $\begin{array}{l}\text { Yes } \\
\text { No }\end{array}$ & $\begin{array}{r}205 \\
1,627\end{array}$ & $\begin{array}{r}14.15 \% \\
7.99 \%\end{array}$ & $\begin{array}{l}1.897 * *(1.232,2.922) \\
1.000\end{array}$ & $\begin{array}{l}9.27 \% \\
4.00 \%\end{array}$ & $\begin{array}{l}2.455 * * *(1.440,4.184) \\
1.000\end{array}$ \\
\hline \multicolumn{6}{|l|}{ Drug abuse } \\
\hline $\begin{array}{l}\text { Yes } \\
\text { No }\end{array}$ & $\begin{array}{r}34 \\
1,798\end{array}$ & $\begin{array}{r}29.41 \% \\
8.29 \%\end{array}$ & $\begin{array}{l}4.611^{* * * *}(2.164,9.826) \\
1.000\end{array}$ & $\begin{array}{r}14.71 \% \\
4.39 \%\end{array}$ & $\begin{array}{l}3.752 * *(1.414,9.951) \\
1.000\end{array}$ \\
\hline \multicolumn{6}{|l|}{ Drug abuse (husband) } \\
\hline $\begin{array}{l}\text { Yes } \\
\text { No }\end{array}$ & $\begin{array}{r}40 \\
1,792\end{array}$ & $\begin{array}{r}22.50 \% \\
8.37 \%\end{array}$ & $\begin{array}{l}3.178 * *(1.485,6.800) \\
1.000\end{array}$ & $\begin{array}{r}12.50 \% \\
4.41 \%\end{array}$ & $\begin{array}{l}3.098 *(1.182,8.121) \\
1.000\end{array}$ \\
\hline
\end{tabular}

Note: $\mathrm{OR}=$ odds ratio; $\mathrm{CI}=$ confidence interval.

$* p<.05 . * * p<.01 . * * * p<.001$.

After multivariate adjustment for covariates using a structured multiphase logistic regression analysis, only six factors remained significant for lifetime IPV (see Table 4): husbands who were young (34 or younger) $(\mathrm{OR}=2.02 ; 95 \%$ Confidence Interval $[\mathrm{CI}]=1.19,3.45)$, indebtedness (adjusted OR $[\mathrm{aOR}]=2.84 ; 95 \% \mathrm{CI}=1.58$, $5.10)$, husband's alcohol abuse $(\mathrm{aOR}=1.70 ; 95 \% \mathrm{CI}=1.08,2.68)$, and women's inlaw conflict $(\mathrm{aOR}=3.87 ; 95 \% \mathrm{CI}=2.25,6.65)$ were most strongly associated with lifetime abuse against the women. Having no income $(\mathrm{aOR}=0.53 ; 95 \% \mathrm{CI}=0.36$, $0.78)$ and receiving more social support $(\mathrm{OR}=0.47$; 95\% $\mathrm{CI}=0.27,0.79)$ were significant protective factors. The Nagelkerke $R^{2}$ suggested that the model explained $8 \%$ of the variance in the lifetime of the relationship. The result of the H-L test was 0.88 , which showed that the model was adequate. 


\section{Table 4}

\section{Structured Multiphase Logistic Regression of Lifetime} and Preceding-Year Intimate Partner Violence (IPV)

\begin{tabular}{|c|c|c|}
\hline Variable & $\begin{array}{c}\text { Adjusted OR } \\
\text { (95.0\% CI for OR) Lifetime IPV }\end{array}$ & $\begin{array}{l}\text { Adjusted OR } \text { OR }^{\mathrm{a}}(95.0 \% \mathrm{CI} \\
\text { for OR) Preceding-Year IPV }\end{array}$ \\
\hline Phase 1 & $\begin{array}{l}(n=1,805, \text { Nagelkerke } \\
\left.\quad R^{2}=0.8 \%, p^{\mathrm{b}}=1.000\right)\end{array}$ & $\begin{array}{l}(n=1,805, \text { Nagelkerke } \\
\left.\quad R^{2}=2.7 \%, p^{\mathrm{b}}=1.000\right)\end{array}$ \\
\hline \multicolumn{3}{|c|}{$\begin{array}{l}\text { Age group of husband } \\
\text { (for lifetime IPV) }\end{array}$} \\
\hline \multicolumn{3}{|c|}{ Wife (for preceding-year IPV) } \\
\hline Younger than 34 & $2.023^{* *}(1.188,3.446)$ & $4.690 * * *(1.985,11.083)$ \\
\hline 35 to 54 & $1.113(0.762,1.625)$ & $2.836 *(1.278,6.290)$ \\
\hline 55 or older & 1.000 & 1.000 \\
\hline Phase 2 & $\begin{array}{l}(n=1,706, \text { Nagelkerke } \\
\left.\quad R^{2}=4 \%, p^{\mathrm{b}}=.933\right)\end{array}$ & $\begin{array}{l}(n=1,718, \text { Nagelkerke } \\
\left.\quad R^{2}=5 \%, p^{\mathrm{b}}=.974\right)\end{array}$ \\
\hline \multicolumn{3}{|l|}{ Income group } \\
\hline No income & $0.526 * * *(0.358,0.775)$ & $0.509 * *(0.309,0.839)$ \\
\hline$\$ 4,999$ or below & $0.566(0.303,1.059)$ & $0.249 *(0.076,0.817)$ \\
\hline$\$ 5,000$ or above & 1.000 & 1.000 \\
\hline \multicolumn{3}{|l|}{ Debt } \\
\hline Indebtedness & $2.835^{* * *}(1.576,5.100)$ & \\
\hline Not in debt & 1.000 & \\
\hline Phase 3 & $\begin{array}{r}(n=1,743, \text { Nagelkerke } \\
\left.R^{2}=5.4 \%, p^{\mathrm{b}}=.333\right)\end{array}$ & $\begin{array}{l}(n=1,798, \text { Nagelkerke } \\
\left.R^{2}=8.1 \%, p^{\mathrm{b}}=.722\right)\end{array}$ \\
\hline Social support & $0.466^{* *}(0.274,0.791)$ & $0.321 * * *(0.161,0.639)$ \\
\hline \multicolumn{3}{|c|}{ Alcohol abuse (husband) } \\
\hline Yes & $1.698 *(1.076,2.681)$ & $2.074 *(1.193,3.603)$ \\
\hline No & 1.000 & 1.000 \\
\hline Phase 4 & $\begin{array}{r}(n=1,756, \text { Nagelkerke } \\
\left.R^{2}=7.9 \%, p^{\mathrm{b}}=.882\right)\end{array}$ & $\begin{array}{r}(n=1,814, \text { Nagelkerke } \\
\left.R^{2}=9.7 \%, p^{\mathrm{b}}=.423\right)\end{array}$ \\
\hline \multicolumn{3}{|c|}{ Women's in-law conflict } \\
\hline Yes & $3.869 * * *(2.252,6.646)$ & $3.659 * * *(1.880,7.123)$ \\
\hline No & 1.000 & 1.000 \\
\hline
\end{tabular}

Note: $\mathrm{OR}=$ odds ratio $\mathrm{CI}=$ confidence interval.

a. Variables in Phase 1 were adjusted by other significant variables in Phase 1. Variables in Phase 2 were adjusted by variables significant in Phase 1 or 2 . Variables in Phase 3 were adjusted by variables significant in Phase 1 or 2 or 3 and so on.

b. $p$ value by the Hosmer \& Lemeshow test.

$* p<.05 . * * p<.01 . * * * p<.001$.

For the preceding-year IPV, after we controlled for other factors with the multiple logistic regression models, young women (aOR for age under $34=4.69 ; 95 \%$ $\mathrm{CI}=1.99,11.08$; aOR for age 35 to $54=2.84 ; 95 \% \mathrm{CI}=1.28,6.29$ ), husband's alcohol abuse $(\mathrm{aOR}=2.07 ; 95 \% \mathrm{CI}=1.19,3.60)$, and women's in-law conflict $(\mathrm{aOR}=$ $3.66 ; 95 \% \mathrm{CI}=1.88,7.12)$ were most strongly associated with IPV that had occurred 
Table 5

Structured Multiphase Logistic Regression of Women's In-Law Conflict

\begin{tabular}{|c|c|c|}
\hline Variable & $\begin{array}{c}\text { Adjusted OR }{ }^{\mathrm{a}} \\
(95.0 \% \mathrm{CI} \text { for OR) }\end{array}$ & $p$ \\
\hline \multicolumn{3}{|c|}{ Phase $1\left(n=1,841\right.$, Nagelkerke $\left.R^{2}=1.7 \%, p^{\mathrm{b}}=1.000\right)$} \\
\hline \multicolumn{2}{|c|}{ Education (husband) } & .007 \\
\hline F3 or below & $0.610(0.320,1.165)$ & .135 \\
\hline $\mathrm{F} 4$ to $\mathrm{F} 7$ & $1.279(0.668,2.449)$ & .458 \\
\hline Tertiary or above & 1.000 & \\
\hline \multicolumn{3}{|c|}{ Phase $2\left(n=1,753\right.$, Nagelkerke $\left.R^{2}=3.8 \%, p^{\mathrm{b}}=.816\right)$} \\
\hline \multicolumn{3}{|c|}{ Work status } \\
\hline Unemployed & $2.356(1.200,4.625)$ & .013 \\
\hline Employed & 1.000 & \\
\hline \multicolumn{2}{|l|}{ Income group } & .001 \\
\hline No income & $0.333(0.158,0.699)$ & .004 \\
\hline$\$ 4,999$ or below & $1.163(0.569,2.376)$ & 679 \\
\hline$\$ 5,000$ or above & 1.000 & \\
\hline \multicolumn{3}{|c|}{ Phase $3\left(n=1,835\right.$, Nagelkerke $\left.R^{2}=6.8 \%, p^{\mathrm{b}}=.559\right)$} \\
\hline \multicolumn{3}{|c|}{ Alcohol abuse } \\
\hline Yes & $2.801(1.353,5.801)$ & .006 \\
\hline No & 1.000 & \\
\hline \multicolumn{3}{|l|}{ Drug abuse } \\
\hline Yes & $3.250(1.188,8.894)$ & .022 \\
\hline No & 1.000 & \\
\hline \multicolumn{3}{|c|}{ Phase $4\left(n=1,858\right.$, Nagelkerke $\left.R^{2}=21.7 \%, p^{\mathrm{b}}=.925\right)$} \\
\hline \multicolumn{3}{|c|}{ Husband's in-law conflict } \\
\hline Yes & $22.860(12.657,41.288)$ & .000 \\
\hline No & 1.000 & \\
\hline
\end{tabular}

Note: $\mathrm{OR}=$ odds ratio $\mathrm{CI}=$ confidence interval.

a. Variables in Phase 1 were adjusted by other significant variables in Phase 1. Variables in Phase 2 were adjusted by variables significant in Phase 1 or 2 . Variables in Phase 3 were adjusted by variables significant in Phase 1 or 2 or 3 and so on.

b. $p$ value by the Hosmer \& Lemeshow test.

in the preceding year. Again, having no or low income $(\mathrm{aOR}=0.51 ; 95 \% \mathrm{CI}=0.31$, 0.84 and $\mathrm{aOR}=0.25 ; 95 \% \mathrm{CI}=0.08,0.82$, respectively) and receiving more social support $(\mathrm{aOR}=0.32 ; 95 \% \mathrm{CI}=0.16,0.64)$ were significant protective factors. The Nagelkerke $R^{2}$ suggested that the model explained $9.7 \%$ of the variance in the previousyear violence. The result of the H-L test was 0.423 , which showed that the model was adequate (see Table 5).

After controlling for other factors with multiple logistic regression models, husband's level of education (F4 to F7) was a significant risk factor of women's in-law conflict when compared to those having a lower level of education. Respondent's working status, 
income, and alcohol and drug abuse remained strongly associated with women's in-law conflict. The husband's in-law conflict had the strongest association with women's inlaw conflict $(\mathrm{aOR}=22.86 ; 95 \% \mathrm{CI}=12.66,41.29)$. The Nagelkerke $R^{2}$ suggested that the model explained $21.7 \%$ of the variance in women's in-law conflict. The result of the H-L test was 0.925 , which showed that the model was adequate.

\section{Discussion}

\section{Prevalence of IPV}

The lifetime and preceding-year prevalence rates of violence against women were $8.5 \%$ and $4.6 \%$, respectively. These figures were comparable to the prevalence rates of spousal violence found in other victimization studies, which have ranged from $1.8 \%$ to $16 \%$ (Hicks \& Li, 2003; Leung et al., 1999; Leung et al., 2003).

\section{Risk Factors}

Consistent with other studies (Goodwin, Gazmararian, Johnson, Gilbert, \& Saltzman, 2000; Hedin, 2000; Martin, Mackie, Kupper, Buescher, \& Moracco, 2001; Muhajarine \& D'Arcy, 1999; Tang, 1999), youth was found to be a risk factor for IPV. In particular, being younger than 34 was associated with an increased risk of IPV. A woman was at higher risk for lifetime IPV if she had financial problems, such as being in debt. This was consistent with findings from past research that showed that women who have more financial worries are more likely to suffer from domestic violence (Bullock, Mears, Woodcock, \& Record, 2001). Husband's abuse of alcohol was a strong risk factor of lifetime and preceding-year IPV, which was also consistent with existing studies (Jasinski, 2004; Liu \& Zhang, 2005; Parish et al., 2004; Xu et al., 2005).

Unlike some other studies (Leung et al., 1999; Parish et al., 2004; Xu et al., 2005; Yick, 2000), finance-related factors such as unemployment or low socioeconomic status were not found to be risk factors for violence against women. Both respondents and their partners who were employed, and thus earned more income, were at higher risk for IPV. Although we controlled for other factors with the multiple logistic regression models, a woman with higher income was still at higher risk for both lifetime and preceding-year IPV. It is possible that the more financially competent women are, the more likely they may be to fight for autonomy and negotiate for independence. This may result in more spousal conflict or violence if their male partners are not able to cope with these appeals. Of course, this does not imply a need to lower women's socioeconomic status. Rather, society has to change men's attitudes so that they will respect women's changing status.

Receipt of more social support was a significant protective factor. A lack of legal and social support for battered women makes it difficult for them to disclose spousal 
violence and thus leave an abusive relationship (Xu, 1997; Xu et al., 2005). This is particularly true for battered women growing up in rural areas of China (Xu et al., 2005). The results of the current study suggest that more social support will thus prevent women from being further abused by their partners.

After controlling for covariates, women's in-law conflict remained the variable with the strongest association to lifetime and preceding-year violence. This study provides empirical data that confirm the relationship between women's in-law conflict and violence against women. In explaining women's in-law conflict as a risk factor, Fernandez (1997) used the concept of "conflicting identities" to label the change in status of the mother-in-law from being a victim when she was a young daughter-in-law to being a batterer when she becomes a mother-in-law. This highlights the change in power status that women experience as they move between family roles. However, it does not explain how this would become a risk factor for violence against women. In fact, in a traditional Chinese family, the power status of a woman does not change as she moves from being a daughter-in-law to a motherin-law because she retains the structurally subordinated identity of being a woman. She is subordinate to the man, who is the head of the family. According to Confucius, "woman yields obedience to the instructions of man, and helps to carry out his principles. ... When young, she must obey her father and elder brother; when married she must obey her husband; when her husband is dead, she must obey her son" (Pearson \& Leung, 1995, p. 4). It is very common for a mother-in-law to follow the will of her son by disciplining a wife who creates in-law conflict. Chinese women are socialized to identify with men and their interests (hooks, 1989). Consequently, they could be perpetrators of oppression in their roles as superiors in racial/ethnic, class, generational, and other hierarchies. Violence against women is a product of the interlocking systems of gender and generational hierarchies in the family (Fernandez, 1997).

Several risk factors for women's in-law conflict were identified in this study. After controlling for other factors with the multiple logistic regression models, the higher education of husband, unemployment of women, a woman who earned more income, women's abuse of alcohol and drugs, and husband's in-law conflict were strongly associated with women's in-law conflict. It is difficult to determine whether women's abuse of alcohol and drugs are truly risk factors or dysfunctional behaviors that help them cope with violence and conflict. Whichever is the case, the health of abused women deserves considerable attention from health professionals.

The husband's and women's in-law conflict could be connected in two ways. First, not only is stress and conflict in the spousal relationship likely intensified by in-law conflict, but also, this spousal conflict may be exacerbated if conflict is present vis-à-vis both sets of in-laws. If one member of the couple is in conflict with his or her in-laws, it may be perceived by the spouse as being disrespectful to their parents. Where in-law conflict is happening on both sides of the family, the perceived disrespect and resulting stress and conflict between the couple may be doubly intensified. The other possibility 
is that husbands who are in conflict with their in-laws may reduce contact with them. This would also mean that the woman's contact with her family is likely reduced since, as noted earlier, women in Chinese society are subordinate to their husbands and are thus unlikely to bypass their husband to make contact with their family. As a result, her social support network will have been weakened. As the current study has shown, with less social support, a woman's risk for IPV is increased.

\section{Implications for Research and Violence Prevention}

Our study is among the first to examine the correlates of women's in-law conflict with IPV against women in a cohort of Chinese women with a large populationbased representative sample. It is important at this juncture to emphasize that not all Chinese relationships with in-laws are conflictual. Indeed, a small proportion of respondents (4.9\% female and 3.6\% male) reported having conflict with their inlaws in the preceding year. However, our findings have important implications for prevention and detection of IPV in Chinese communities.

IPV is not a stand-alone problem. Rather, it correlates with other forms of violence against women, such as in-law conflict, which reside within the same familial hierarchical structure that is deeply rooted in Chinese culture. The screening and assessment of IPV in Chinese families should include in-law conflict, which is a form of violence as well as a risk factor of IPV. As has been recommended by some organizations of health professionals (American College of Obstetricians and Gynecologists, 2002; British Medical Association, 1998), violence against women by different family members and using various types of abuse should be taken into account in universal screening for IPV in health care settings. This should not be limited to IPV but should extend to all forms of violence against women. Risk assessment of IPV against women should also take into account indebtedness among women and alcohol abuse among their husbands. Psychosocial support programs should be provided for women. The perpetrators of partner violence and in-law conflict should also have access to such programs. Family-based interventions such as home visitations (Olds et al., 1999) may also be appropriate.

In-law conflict as a form of violence against women likely reinforces a familial culture of using violence as a means to resolve conflict and thus creates a "harmful traditional practice" (United Nations General Assembly, 2006). Hence, a failure to stop in-law conflict would be counterproductive to preventing violence against women.

A major limitation of this study is that in-law conflict was measured by a single item that asked participants and their partners to report the number of incidents of conflict with their parents-in-law during the previous 12 months. This may have led to an underestimation of the prevalence of in-law conflict because the term conflict may be subject to different interpretations. Other forms of abuse should also be studied when assessing in-law conflict. For example, some items related to in-law emotional abuse have 
recently been explored, such as isolation, social and economic control, domestic servitude, awareness or support of IPV, and direct physical abuse (Raj et al., 2006). More research is needed to further explore the construct of in-law abuse and conflict.

Despite this limitation, this study provides preliminary evidence that women's inlaw conflict is a risk factor for IPV. Even though relationship harmony is valued in Chinese tradition, certain women, in particular those who have conflicts with their in-laws, appear to be at an especially high risk. It seems that in-law conflict is a common phenomenon among Chinese and some Asian cultures. The paucity of research on in-law conflict in other ethnic groups suggests that the influence of extended family members may be underestimated in cultures that emphasize individualism. Hence, it may be a universal phenomenon that is more explicit in collectivist societies, such as Chinese societies. It would be worthwhile to examine whether inlaw conflict is a risk factor for IPV in different cultures.

\section{References}

American College of Obstetricians and Gynecologists. (2002). Guidelines for women's health care (2nd ed.). Washington, DC: Author.

British Medical Association. (1998). Domestic violence: A health care issue? Retrieved October 12, 2006, from www.bma.org.uk/ap.nsf/Content/domesticviolence1998

Bullock, L. F., Mears, J. L., Woodcock, C., \& Record, R. (2001). Retrospective study of the association of stress and smoking during pregnancy in rural women. Addictive Behaviors, 26, 405-413.

Chan, K. L. (2004). Correlates of wife assault in Hong Kong Chinese families. Violence and Victims, 19, 189-201.

Chan, K. L. (2006). The Chinese concept of face and violence against women. International Social Work, 49, 65-73.

Coben, J. H., Forjuoh, S. N., \& Gondolf, E. W. (1999). Injuries and health care use in women with partners in batterer intervention programs. Journal of Family Violence, 14, 83-94.

Counts, D. A., Brown, J. K., \& Campbell, J. (Eds.). (1999). To have and to hit: Cultural perspectives on wife beating (2nd ed.). Urbana: University of Illinois Press.

Dasgupta, S. D. (2000). Charting the course: An overview of domestic violence in the South Asian community in the United States. Journal of Social Distress and the Homeless, 9, 173-185.

Fernandez, M. (1997). Domestic violence by extended family members in India: Interplay of gender and generation. Journal of Interpersonal Violence, 12, 433-455.

Goodwin, M. M., Gazmararian, J. A., Johnson, C. H., Gilbert, B. C., \& Saltzman, L. E. (2000). Pregnancy intendedness and physical abuse around the time of pregnancy: Findings from the pregnancy risk assessment monitoring system, 1996-1997. PRAMS Working Group. Pregnancy Risk Assessment Monitoring System. Maternal and Child Health Journal, 4(2), 85-92.

Hedin, L. W. (2000). Postpartum, also a risk period for domestic violence. European Journal of Obstetrics, Gynecology, and Reproductive Biology, 89, 41-45.

Hicks, M. H., \& Li, Z. (2003). Partner violence and major depression in women: A community study of Chinese Americans. Journal of Nervous and Mental Disease, 191, 722-729.

hooks, b. (1989). Talking back : Thinking feminist, thinking black. Boston: South End Press.

Hosmer, D. W., \& Lemeshow, S. (2000). Applied logistic regression (2nd ed.). New York: John Wiley \& Sons. Jasinski, J. L. (2004). Pregnancy and domestic violence: A review of the literature. Trauma, Violence and Abuse, 5, 47-64. 
Kantor, G. K., \& Straus, M. A. (1999). Report on the USAF Family Needs Screener. Durham: Family Research Laboratory, University of New Hampshire.

Krug, E. G., Dahlberg, L. L., Mercy, J. A., Zwi, A. B., \& Lozaro, R. (Eds.). (2002). World report on violence and health. Geneva, Switzerland: World Health Organization.

Lam, C. L. K., Fong, D. Y. T., Lauder, I. J., \& Lam, T. P. (2002). The effect of health-related quality of life (HRQOL) on health service utilization of a Chinese population. Social Science and Medicine, 55, 1635-1646.

Lee, D. T. S., Yip, A. S. K., Leung, T. Y. S., \& Chung, T. K. H. (2004). Ethnoepidemiology of postnatal depression: Prospective multivariate study of sociocultural risk factors in a Chinese population in Hong Kong. British Journal of Psychiatry, 184, 34-40.

Leung, T. W., Ng, E. H. Y., Leung, W. C., \& Ho, P. C. (2003). Intimate partner violence among infertile women. International Journal of Gynaecology and Obstetrics, 83, 323-324.

Leung, W. C., Leung, T. W., Lam, Y. Y., \& Ho, P. C. (1999). The prevalence of domestic violence against pregnant women in a Chinese community. International Journal of Gynaecology and Obstetrics, 66, 23-30.

Liu, M. (2002). Rebellion and revenge: The meaning of suicide of women in rural China. International Journal of Social Welfare, 11, 300-309.

Liu, M., \& Chan, C. (1999). Enduring violence and staying in marriage: Stories of battered women in rural China. Violence Against Women, 5, 1469-1492.

Liu, M., \& Zhang, L. (2005). Personal experiences and public attitudes: Findings from the national survey. In L. Huang \& W. Rong (Eds.), Combating domestic violence against women: China in action (pp. 125-142). Beijing: China Social Sciences Press.

Martin, S. L., Mackie, L., Kupper, L. L., Buescher, P. A., \& Moracco, K. E. (2001). Physical abuse of women before, during, and after pregnancy. Journal of the American Medical Association, 285 , 1581-1584.

Mercy, J. A., Rosenberg, M. L., Powell, K. E., Broome, C. V., \& Roper, W. L. (1993). Public health policy for preventing violence. Health Affairs, 12(4), 7-29.

Muhajarine, N., \& D'Arcy, C. (1999). Physical abuse during pregnancy: Prevalence and risk factors. Canadian Medical Association Journal/Journal de l'Association Medicale Canadienne, 160, 1007-1011.

Olds, D. L., Henderson, C. R., Kitzman, H. J., Eckenrode, J. J., Cole, R. E., \& Tatelbaum, R. C. (1999). Prenatal and infancy home visitation by nurses: Recent findings. Future of Children, 9(1), 44-65.

Parish, W. L., Wang, T., Laumann, E. O., Pan, S., \& Luo, Y. (2004). Intimate partner violence in China: National prevalence, risk factors and associated health problems. International Family Planning Perspectives, 30(4), 174-181.

Pearson, V., \& Leung, B. K. P. (Eds.). (1995). Women in Hong Kong. Hong Kong: Oxford University Press.

Raj, A., Livramento, K. N., Santana, M. C., Gupta, J., \& Silverman, J. G. (2006). Victims of intimate partner violence more likely to report abuse from in-laws. Violence Against Women, 12, 936-949.

Ramanathan, S. (1996). Violence against women. International Medical Journal, 3, 145-148.

Rianon, N. J., \& Shelton, A. J. (2003). Perception of spousal abuse expressed by married Bangladeshi immigrant women in Houston. Journal of Immigrant Health, 5, 37-44.

Straus, M. A. (1990). The Conflict Tactics Scale and its critics: An evaluation and new data on validity and reliability. In M. A. Straus \& R. J. Gelles (Eds.), Physical violence in American families: Risk factors and adaptations to violence in 8,145 families (pp. 31-54). New Brunswick, NJ: Transaction Publishers.

Straus, M. A. (2004). Cross-cultural reliability and validity of the Revised Conflict Tactics Scales: A study of university student dating couples in 17 nations. Cross-cultural Research, 38, 407-432.

Straus, M. A., Hamby, S. L., Boney-McCoy, S., \& Sugarman, D. B. (1996). The Revised Conflict Tactics Scales (CTS2): Development and preliminary psychometric data. Journal of Family Issues, 17, 283-316.

Straus, M. A., \& Mouradian, V. E. (1999, November). Preliminary psychometric data for the personal and relationships profile (PRP): A multi-scale tool for clinical screening and research on partner violence. 
Paper presented at the annual meeting of the American Society of Criminology, Toronto, Ontario, Canada.

Tang, C. S. K. (1999). Wife abuse in Hong Kong Chinese families: A community survey. Journal of Family Violence, 14, 173-191.

United Nations General Assembly. (2006). In-depth study on all forms of violence against women: Report of the secretary-general. Geneva, Switzerland: United Nations.

Xu, X. (1997). The prevalence and determination of wife abuse in urban China. Journal of Comparative Family Studies, 28, 280-303.

Xu, X., Zhu, F., O'Campo, P., Koenig, M. A., Mock, V., \& Campbell, J. (2005). Prevalence of and risk factors for intimate partner violence in China. American Journal of Public Health, 95, 78-85.

Yick, A. G. (1999). Domestic violence in the Chinese American community: Cultural taboos and barriers. Family Violence \& Sexual Assault Bulletin, 15(4), 16-23.

Yick, A. G. (2000). Predictors of physical spousal/intimate violence in Chinese American families. Journal of Family Violence, 15, 249-267.

Yick, A. G., \& Agbayani-Siewert, P. (2000). Dating violence among Chinese American and White students: A sociocultural context. Journal of Multicultural Social Work, 8, 101-129.

Ko Ling Chan, PhD, is an assistant professor of social work at the University of Hong Kong. He has established his expertise in the area of family violence and has completed a pioneer research project commissioned by the Hong Kong Government to study the prevalence rates and risk factors of spousal and child abuse in Hong Kong, review legislative measures, and validate the risk assessment tool. He has developed research to study culturally specific risk factors of partner violence and child abuse, such as inlaw conflict and face concern.

Douglas A. Brownridge, $\mathrm{PhD}$, is an associate professor in the Department of Family Social Sciences as well as an adjunct professor in the Arthur V. Mauro Center for Peace and Justice at the University of Manitoba and an honorary professor at the University of Hong Kong. He teaches courses on family violence at the undergraduate and graduate levels. His current research includes a focus on violence against women in special populations.

Agnes Tiwari, $\mathrm{PhD}$, is an associate professor in the Department of Nursing Studies and an assistant dean (Education \& Student Affairs) of the Li Ka Shing Faculty of Medicine, University of Hong Kong. Her clinical experience and research activities focus on family violence. She has been actively involved in intimate partner violence prevention and intervention programs in Hong Kong. The outcomes of such programs include a validated screening tool for Chinese women with a history of intimate partner violence and several interventions to prevent partner violence and reduce the adverse impact on Chinese abused women's physical and mental health.

Daniel Y. T. Fong, PhD, is currently an assistant professor in the Department of Nursing Studies of the University of Hong Kong. He is a statistician by training. He has many years of experience in clinical trials and statistical consulting. His research interests are biostatistics, quality of life research, and public health.

Wing-Cheong Leung, MD, graduated from the Medical School of the University of Hong Kong in 1989. He completed specialist training in obstetrics and gynecology at the University of Hong Kong in 1997. He undertook further training in maternal fetal medicine at the University of Toronto, in Canada, in 1999 and University College London, in the United Kingdom, from 2002 to 2003. He is an accredited subspecialist in maternal fetal medicine by the Royal College of Obstetrics and Gynaecology (U.K.). He is currently the consultant obstetrician in Kwong Wah Hospital in Hong Kong. Domestic violence in pregnancy is one of his major research interests. 